\title{
$\gamma$-Tocopherol Accelerated Sodium Excretion in a Dose-Dependent Manner in Rats with a High Sodium Intake
}

\author{
Harumi Uto-Kondo ${ }^{1}$, Mariko Tani ${ }^{1}$, Chikako Kiyose ${ }^{2}$, Mika Usuda ${ }^{1}$, Chie Taguchi ${ }^{1}$, \\ Maiko Hasegawa ${ }^{1}$, Naoko Machida ${ }^{1}$, Yoshimi Kishimoto ${ }^{1}$, Hisako Saito ${ }^{3}$, Tadahiko Ueda ${ }^{4}$, \\ Osamu Igarashi ${ }^{5}$, and Kazuo Kondo ${ }^{1, *}$ \\ ${ }^{1}$ Institute of Environmental Science for Human Life, Ochanomizu University, Tokyo 112-8610, Japan \\ ${ }^{2}$ Department of Applied Bioscience, Kanagawa Institute of Technology, Kanagawa 243-0292, Japan \\ ${ }^{3}$ Department of Education, Hirosaki University, Aomori 036-8560, Japan \\ ${ }^{4}$ Yamano Beauty College, Tokyo 151-8539, Japan \\ ${ }^{5}$ Department of Life Science, Ibaraki Christian University, Ibaraki 319-1295, Japan
}

Received 14 December, 2006; Accepted 9 May, 2007

\begin{abstract}
Summary We have previously reported that $\gamma$-tocopherol $(\gamma$-Toc) displays a natriuretic potency in rats fed a $\mathrm{NaCl}$ diet and administered $20 \mathrm{mg} \gamma$-Toc. In this study, we investigated whether $\gamma$-Toc has natriuretic potency at a dose lower or higher than $20 \mathrm{mg}$ in rats given a $\mathrm{NaCl}$ diet. Male rats were fed a control diet or a $\mathrm{NaCl}$ diet and administered either placebo or 10,20 or $40 \mathrm{mg}$ of $\gamma$-Toc. The rat urine was collected for 24 hours (divided into 6 hour periods) and the 2,7,8-trimethyl-2-(2'-carboxyethyl)-6-hydroxychroman ( $\gamma$-CEHC) level, the sodium excretion content, and the urine volume were determined. The 24 -hour $\gamma$-CEHC and sodium levels in the urine of the $\mathrm{NaCl}$ groups given $20 \mathrm{mg}$ or $40 \mathrm{mg} \gamma$-Toc were significantly higher than those in the placebo group. The peak levels of urine sodium and $\gamma$-CEHC in the $\mathrm{NaCl}$ group given $40 \mathrm{mg} \gamma$-Toc appeared at $0-6 \mathrm{~h}$, which was a more rapid increase than that seen in the group given $20 \mathrm{mg} \gamma$-Toc. The 24-hour urine volumes of the $\mathrm{NaCl}$ groups given 10 and $20 \mathrm{mg} \gamma$-Toc were significantly higher than the urine volume of the placebo group. Our findings suggested that $\gamma$-Toc increased sodium excretion in a dose-dependent manner in rats fed a $\mathrm{NaCl}$ diet. Moreover, a high dose of $\gamma$-Toc may accelerate its metabolism and cause an increase in the rate of sodium excretion.
\end{abstract}

Key Words: $\gamma$-tocopherol, $\gamma$-CEHC, natriuretic hormone, sodium excretion

\section{Introduction}

Dietary salt intake plays a major role in the onset and development of hypertension [1,2]. Observational studies have shown a positive relationship between salt intake and blood pressure [3]. Salt intake has been reported to be high

\footnotetext{
*To whom correspondence should be addressed.

Tel: +81-3-5978-5812 Fax: +81-3-5978-2694

E-mail: kondo.kazuo@ocha.ac.jp
}

in the Japanese population [4] and it is thus presumed that there is a high incidence of hypertension in this country.

Natriuretic hormone is an effective vasodilator and induces diuretic. As a pharmacological treatment, the hormone improves hypertension and inhibits the development of cardiac failure $[5,6]$. The $\gamma$-tocopherol $(\gamma$-Toc) urinary metabolite, 2,7,8-trimethyl-2-(2'-carboxyethyl)-6-hydroxychroman $(\gamma$ CEHC), plays a role similar to natriuretic hormones [7-9] (Fig. 1). $\gamma$-Toc and $\alpha$-Toc are rich in foods such as nuts and vegetable oils. However, $\alpha$-Toc exists more abundantly in animal plasma and tissue and is more biologically active 


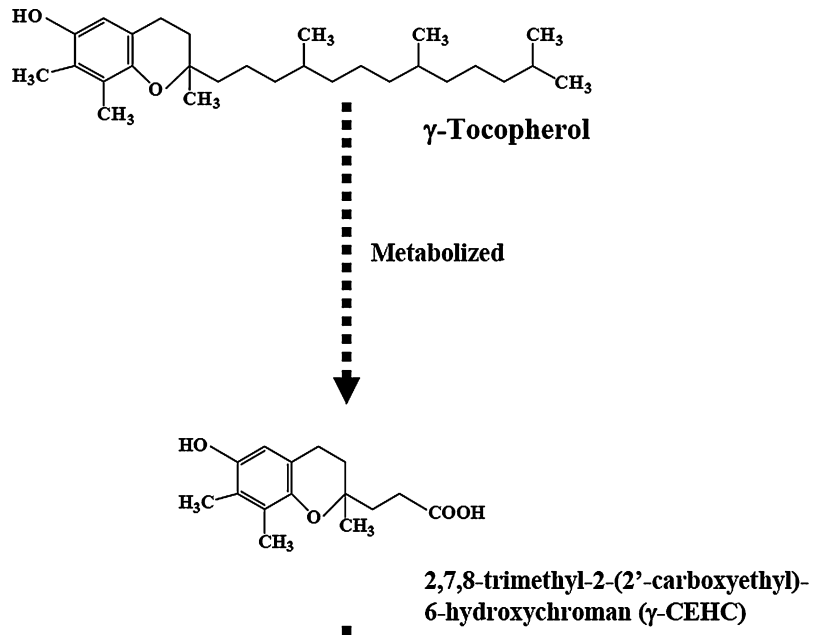

Natriuretic hormone

\section{The effect of $\gamma$-Toc on sodium excretion into urine}

Fig. 1. $\quad \gamma$-Tocopherol $(\gamma$-Toc) is metabolized to 2,7,8-trimethyl-2(2'-carboxyethyl)-6-hydroxychroman $(\gamma$-CEHC), which is a natriuretic hormone.

than $\gamma$-Toc. This is due to the presence of $\alpha$-Toc transfer protein in the cytoplasm of hepatocytes. This protein clearly discriminates $\alpha$-Toc from $\gamma$-Toc $[10,11]$. In addition, absorbed $\gamma$-Toc rapidly disappears from plasma and is metabolized to $\gamma$-CEHC.

Recently, we showed that the oral administration of $20 \mathrm{mg}$ $\gamma$-Toc could cause natriuresis and diauresis in rats given $5 \%$ $\mathrm{NaCl}$ diet [12]. $\gamma$-Toc acts as a natriuretic hormone precursor in these circumstances. However, it was unknown if $\gamma$-Toc has natriuretic potency at a dose lower or higher than $20 \mathrm{mg}$ in rats given a $\mathrm{NaCl}$ diet. In this study, we investigated whether $\gamma$-Toc could accelerate sodium excretion in a dosedependent manner in rats given a $5 \% \mathrm{NaCl}$ diet.

\section{Materials and Methods}

\section{Materials}

$\gamma$-Toc and $\gamma$-CEHC were donated by Eisai Co. (Tokyo, Japan). All agents used in this study were either HPLC grade or reagent grade.

\section{Experimental animals}

This experiment was carried out under the guidelines of the Animal Committee of Ochanomizu University. 7-week-old male Sprague-Dawley rats $(n=44)$ were purchased from
Clea Japan Co. Ltd. (Tokyo, Japan) and kept individually in stainless steel cages at $22 \pm 1^{\circ} \mathrm{C}$ and $55 \%$ humidity with a $12 \mathrm{~h}$ light/dark cycle.

The rats were fed a commercial diet (CE-2; Clea Japan Co., Ltd.) for 1 week. The rats were subsequently divided into 2 groups. The control group was fed a vitamin Edeficient diet (AIN-76 modified by Eisai.Co.; Funabashi Noujyou, Chiba, Japan), and the other group was fed a high$\mathrm{NaCl}$ diet ( $5 \% \mathrm{NaCl}$ added to the control diet ) for the next 4 weeks. The vitamin E-defecient diet consisted of $236.8 \mathrm{~g}$ sucrose, $236.8 \mathrm{~g}$ glucose, $189.5 \mathrm{~g}$ casein (vitamin free), $142.1 \mathrm{~g}$ cornstarch, $47.4 \mathrm{~g}$ filter paper, $33.2 \mathrm{~g}$ mineral mixture, $9.5 \mathrm{~g}$ vitamin mixture except vitamin $\mathrm{E}, 2.8 \mathrm{~g}$ dl-methyonine, $1.9 \mathrm{~g}$ choline bitartate, and $100 \mathrm{~g}$ stripped corn oil. The $\mathrm{NaCl}$ diet consisted of the same ingredients as the vitamin E-deficient diet with the addition of $50 \mathrm{~g} \mathrm{NaCl}$ per kilogram. Water was given ad libitum; however, food was given in a regimen of $20 \mathrm{~g} /$ day for the initial week and $25 \mathrm{~g} /$ day for the following 3 weeks.

\section{Study population and design}

These 2 groups were subdivided into 4 groups after 12 hours of fasting. The placebo group $(n=5)$ was given a $0.5 \mathrm{ml}$ dosage of stripped corn oil, while $\gamma$-Toc group $(n=6)$ was given $0.5 \mathrm{ml}$ of stripped corn oil containing 10,20 , $40 \mathrm{mg}$ of $\gamma$-Toc. After the oral administration of $\gamma$-Toc or a placebo, the rats were housed individually in metabolic cages.

\section{Collection of urine samples}

Urine was collected in flasks at $6 \mathrm{~h}$ intervals for $24 \mathrm{~h}$. The urine was cooled with dry ice after collection. All urine samples were immediately stored at $-20^{\circ} \mathrm{C}$ until further analyzed.

Determination of the urine volume, sodium content, and potassium content in rat urine

The urine volume and creatinine content were measured after each urine collection. The creatinine in each urine sample was measured by the Jaffe method [13, 14] (Hitachi auto analyzer 7011, Hitachi Medical Co., Tokyo, Japan). The sodium and potassium contents in the urine were determined by an electrode method $[15,16]$ (Hitachi auto analyzer 7011, Hitachi Medical Co., Tokyo, Japan).

Extraction of $\gamma$-CEHC from the rat urine and the chromatographic apparatus and conditions

$\gamma$-CEHC content in the urine was analyzed by the method reported by Kiyose et al. [15]. $\gamma$-CEHC in the urine was treated with $3 \mathrm{~N}$ methanolic $\mathrm{HCl}$ to hydrolyze conjugates and to promote esterification. $\gamma$-CEHC-methyl ester in the urine was determined by HPLC-ECD. The HPLC system consisted of the Shiseido intelligent HPLC pump (SI-2) 
(Shiseido Co., Kyoto, Japan), JASCO intelligent sampler (AS-950-10), a column oven (860-10), and an integrator (807-IT) (JASCO Co., Tokyo, Japan) while applying a potential of $+0.6 \mathrm{~V}$ vs $\mathrm{Ag} / \mathrm{AgCl}$. The $\gamma$-CEHC analysis was performed at $35^{\circ} \mathrm{C}$ using an RP-18T $\mathrm{C} 18$ column $(250 \times 2.0 \mathrm{~mm}$ I.D., IRICA Instruments Inc., Tokyo, Japan). The mobile phase was performed using acetonitrile-water $(40 / 60, \mathrm{v} / \mathrm{v})$ with $50 \mathrm{mM}$ sodium perchlorate at a flow rate of $0.2 \mathrm{ml} / \mathrm{min}$.

\section{Statistical analysis}

Statistical analyses were performed using the Stat View Version 5.0 software package (SAS Institute Inc., NC.). All results were expressed as the mean \pm SEM. The significance between the 8 experimental groups was evaluated using the multivariate ANOVA (MANOVA).

\section{Results}

\section{$\gamma$-CEHC Excretion into Rat Urine}

The $\gamma$-CEHC excretion over the course of $24 \mathrm{~h}$ is shown in Fig. 2. The urine levels of $\gamma$-CEHC in the $\mathrm{NaCl}$ groups given $10 \mathrm{mg} \gamma$-Toc $(283 \pm 60 \mu \mathrm{g} / 24 \mathrm{~h}$ urine; $p<0.01), 20 \mathrm{mg}$ $\gamma$-Toc $(315 \pm 45 \mu \mathrm{g} / 24 \mathrm{~h}$ urine; $p<0.01)$ and $40 \mathrm{mg} \gamma$-Toc $(333 \pm 23 \mu \mathrm{g} / 24 \mathrm{~h}$ urine; $p<0.01)$ were significantly higher than the $\gamma$-CEHC levels in the control groups $(10 \mathrm{mg}$; $89 \pm 22 \mu \mathrm{g} / 24 \mathrm{~h}$ urine, $20 \mathrm{mg} ; 120 \pm 30 \mu \mathrm{g} / 24 \mathrm{~h}$ urine, and $40 \mathrm{mg} ; 156 \pm 38 \mu \mathrm{g} / 24 \mathrm{~h}$ urine). Furthermore, the peak levels of $\gamma$-CEHC in the $\mathrm{NaCl}$ groups given $10 \mathrm{mg}(6-12 \mathrm{~h}$; $p<0.05,12-18 \mathrm{~h} ; p<0.05), 20 \mathrm{mg}(6-12 \mathrm{~h} ; p<0.05)$ and $40 \mathrm{mg} \gamma$-Toc $(0-6 \mathrm{~h} ; p<0.01)$ were significantly higher than the peak levels of the control group at each time period (Fig. 2). The peak level at $6-12 \mathrm{~h}$ in the $\mathrm{NaCl}$ group given $20 \mathrm{mg} \gamma$-Toc was similar to the results from our previous study [12]. The oral administration of $\gamma$-Toc has a positive relationship with $\gamma$-CEHC urine levels in a dose-dependent manner in rats fed control diet $\left(\mathrm{r}^{2}=0.4139, p<0.001\right)$ and $5 \% \mathrm{NaCl} \operatorname{diet}\left(\mathrm{r}^{2}=0.1764, p<0.05\right)$ (Fig. $\left.3 \mathrm{~A}\right)$.

\section{Urine volume}

Fig. 4 shows the changes in the urine volume level throughout the $24 \mathrm{~h}$ period after the oral administration of the placebo or $\gamma$-Toc. There were no significant differences in the urine volume level between the control group given the placebo and the control group given $\gamma$-Toc. However, the 24-h urine volumes levels in the $\mathrm{NaCl}$ group given $10 \mathrm{mg}$ $(35.1 \pm 9.3 \mathrm{ml} ; p<0.05)$ or $20 \mathrm{mg} \gamma$-Toc $(51.4 \pm 12.6 \mathrm{ml}$; $p<0.05)$ were significantly higher than the urine volume level of the $\mathrm{NaCl}$ group given the placebo $(12.5 \pm 1.9 \mathrm{ml})$. Furthermore, the peak urine volumes levels in the $\mathrm{NaCl}$ group given $10 \mathrm{mg} \gamma$-Toc $(12-18 \mathrm{~h} ; p<0.05)$ and $20 \mathrm{mg}(12-$ $18 \mathrm{~h} ; p<0.05)$ were significantly higher at each time period than those in the $\mathrm{NaCl}$ group given a placebo. The peak level
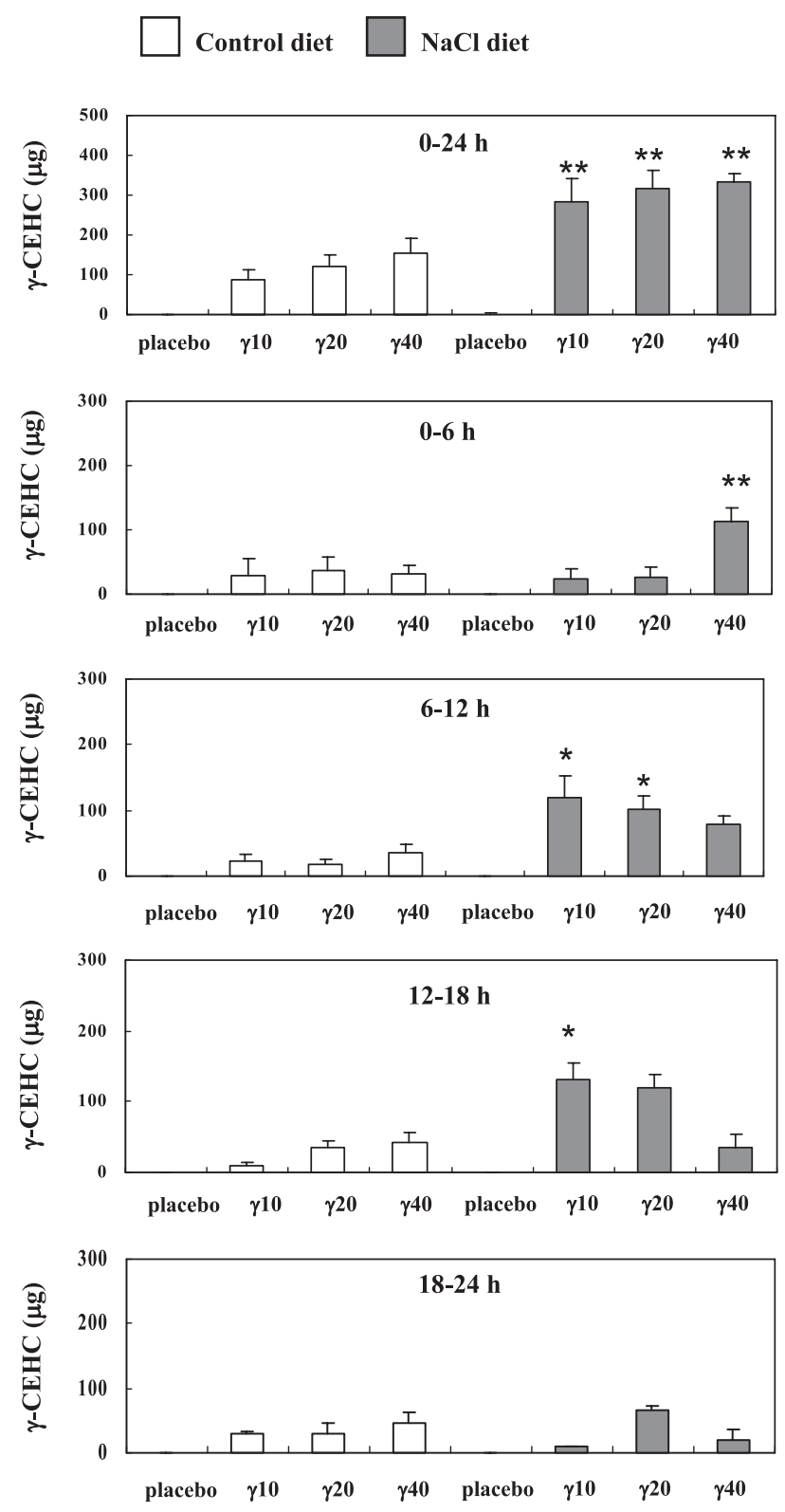

Fig. 2. Changes in 2,7,8-trimethyl-2-(2'-carboxyethyl)-6hydroxychroman $(\gamma$-CEHC) levels in rat urine after the oral administration of placebo or $\gamma$-tocopherol $(\gamma$-Toc). The rats were fed a vitamin E-deficient diet (control) or a $\mathrm{NaCl}$ diet for 4 weeks. In each group, one subgroup was administered a placebo, while the others were given $10 \mathrm{mg}(\gamma 10), 20 \mathrm{mg}(\gamma 20), 40 \mathrm{mg}(\gamma 40)$ of $\gamma$-Toc. After the oral administration of single dose of the placebo or $\gamma$ Toc, the rat urine was collected for $24 \mathrm{~h}$ (divided into $6 \mathrm{~h}$ periods) and then the $\gamma$-CEHC content was measured. The values are the mean \pm SEM. of $4-6$ rats, $* p<0.05$, ${ }^{* *} p<0.01$ vs the control diet group at each time period. 
A
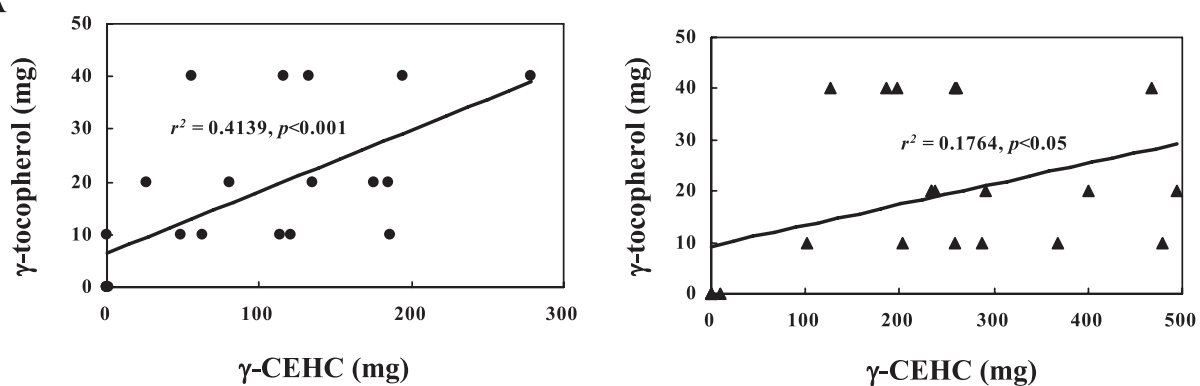

B
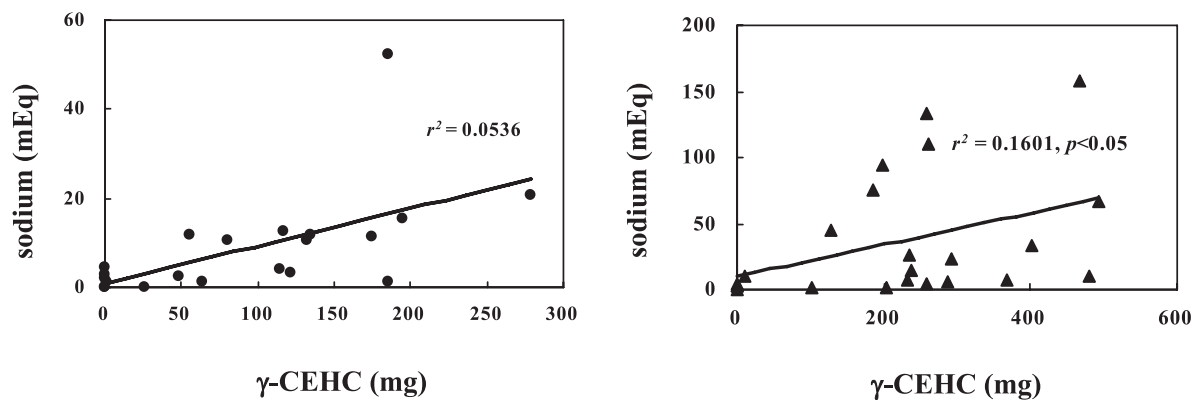

C
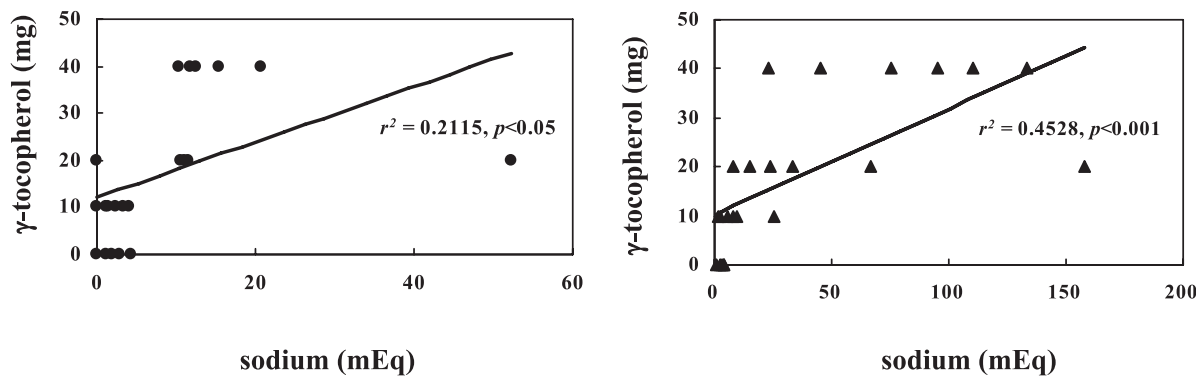

Fig. 3. Correlation between the level of urine sodium and 2,7,8-trimethyl-2-(2'-carboxyethyl)-6-hydroxychroman ( $\gamma$-CEHC) and $\gamma$-Toc. The rats were fed a control diet (closed circle) or $\mathrm{NaCl}$ diet (closed triangle) for 4 weeks. One subgroup was administered a placebo, while the others were given $10,20,40 \mathrm{mg}$ of $\gamma$-Toc. A. Correlation between the urine sodium level and the level of 2,7,8-trimethyl-2-(2'-carboxyethyl)-6-hydroxychroman ( $\gamma$-CEHC) throughout the $24 \mathrm{~h}$ period. These plots display a linear relationship at $r^{2}=0.4139, p<0.001$ (closed circle) and $r^{2}=0.4199, p<0.001$ (closed triangle). B. Correlation between the urine sodium level and the dose of $\gamma$-tocopherol $(\gamma$-Toc) throughout the 24 hour period. These plots display a linear relationship at $r^{2}=0.0536$ (closed circle) and $\mathrm{r}^{2}=0.1601$ (closed triangle). C. Correlation between the level of 2,7,8-trimethyl-2-(2'carboxyethyl)-6-hydroxychroman $(\gamma$-CEHC) and the dose of $\gamma$-tocopherol $(\gamma$-Toc) throughout the $24 \mathrm{~h}$ period. These plots display a linear relationship at $r^{2}=0.2115, p<0.05$ (closed circle) and $r^{2}=0.4528, p<0.001$ (closed triangle).

in the $\mathrm{NaCl}$ group given $20 \mathrm{mg} \gamma$-Toc between $12-18 \mathrm{~h}$ was similar to the results from our previous study [12]. According to these findings, the $\mathrm{NaCl}$ groups given only $10 \mathrm{mg}$ or $20 \mathrm{mg} \gamma$-Toc had higher urine volumes than the rats in the $\mathrm{NaCl}$ groups given $40 \mathrm{mg} \gamma$-Toc or the placebo. On the other hand, no substantial changes were observed in the creatinin content in the rat urine in all experimental groups (data not shown).

\section{Sodium and potassium excretion into rat urine}

We examined the effects of $\gamma$-Toc administration on sodium excretion and potassium excretion in rat urine. $\gamma$-Toc accelerates sodium excretion in a dose-dependent manner in rats with a high sodium intake. The 24-hour sodium levels in the urine of rats given $20 \mathrm{mg} \gamma$-Toc $(1.2 \pm 0.4 \mathrm{mEq} ; p<0.05)$ and $40 \mathrm{mg} \gamma$-Toc $(4.5 \pm 0.7 \mathrm{mEq} ; p<0.01)$ were significantly higher than that the sodium levels in the $\mathrm{NaCl}$ group given a 

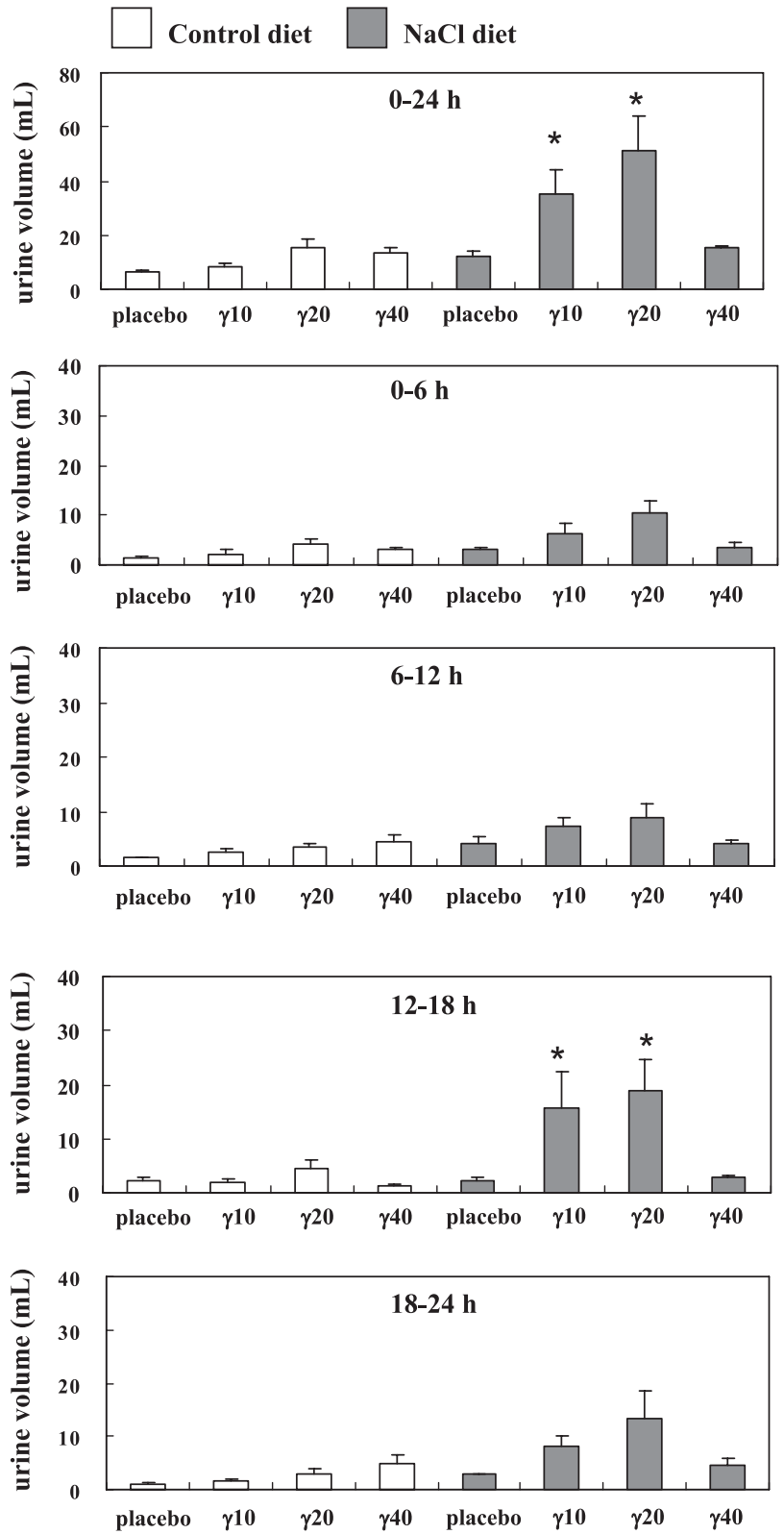

Fig. 4. Changes in the rat urine volume level after the oral administration of placebo and $\gamma$-tocopherol $(\gamma$-Toc). The rats were fed a vitamin E-deficient diet (control) or a $\mathrm{NaCl}$ diet for 4 weeks. In each group, one subgroup was a placebo, while the others were given $10 \mathrm{mg}(\gamma 10)$, $20 \mathrm{mg}(\gamma 20), 40 \mathrm{mg}(\gamma 40)$ of $\gamma$-Toc. After the oral administration of single dose of the placebo or $\gamma$-Toc, the rat urine was collected for $24 \mathrm{~h}$ (divided into $6 \mathrm{~h}$ periods) and the urine volume was determined. The values are the mean \pm SEM of 4-6 rats, ${ }^{*} p<0.05$ vs placebo at each time period.

placebo (Fig. 5). Furthermore, the peak sodium levels in the $\mathrm{NaCl}$ groups given $20 \mathrm{mg} \gamma$-Toc $(12-18 \mathrm{~h} ; p<0.05)$ and $40 \mathrm{mg} \gamma$-Toc $(0-6 \mathrm{~h} ; p<0.01,6-12 \mathrm{~h} ; p<0.05,12-18 \mathrm{~h}$; $p<0.05)$ were significantly higher than the levels in the $\mathrm{NaCl}$
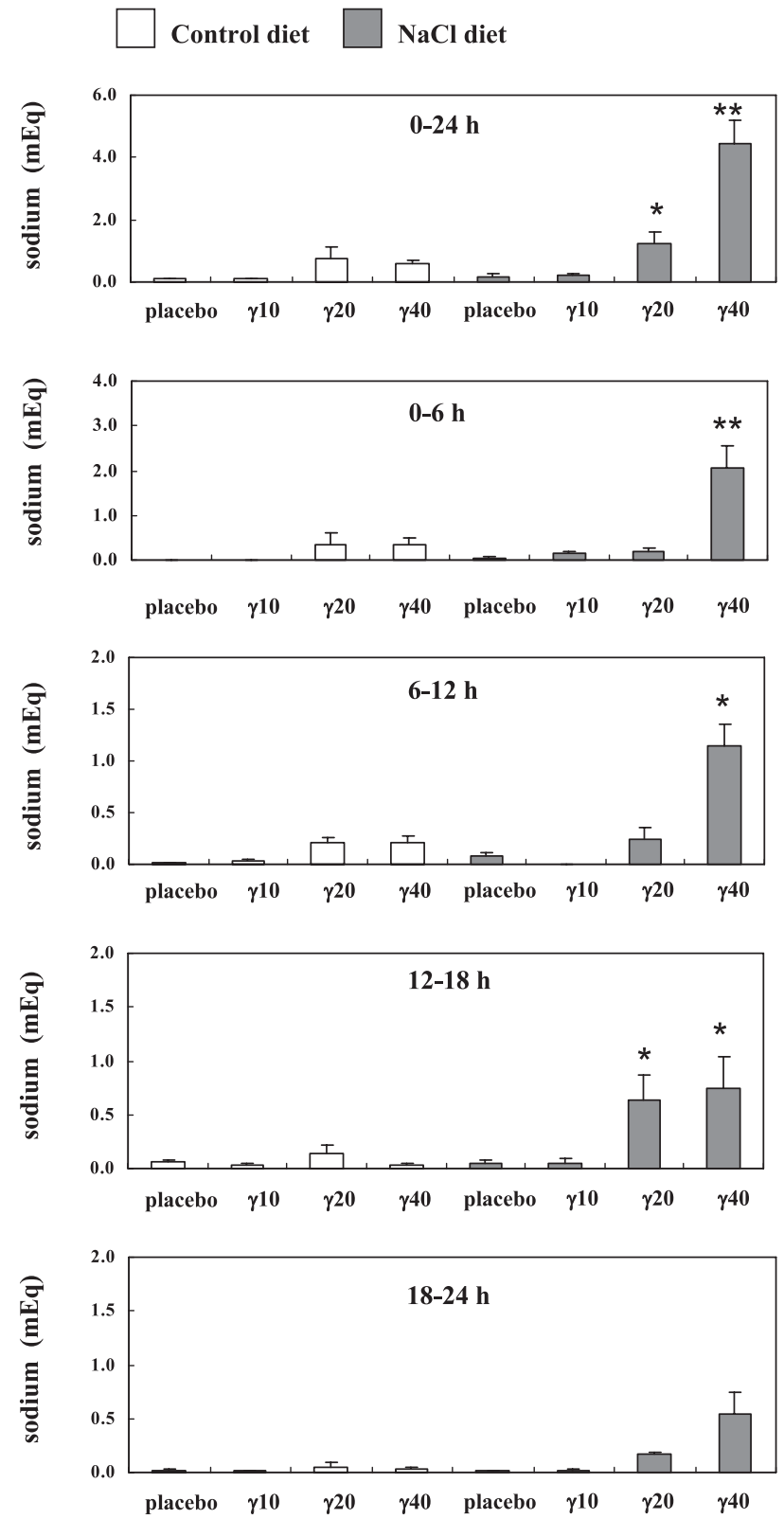

Fig. 5. Changes in the urine sodium levels after the oral administration of a placebo or $\gamma$-tocopherol $(\gamma$-Toc). The rats were fed a vitamin E-deficient diet (control) or a $\mathrm{NaCl}$ diet for 4 weeks. In each group, one subgroup was administered a placebo, while the others were given $10 \mathrm{mg}(\gamma 10), 20 \mathrm{mg}(\gamma 20), 40 \mathrm{mg}(\gamma 40)$ of $\gamma$-Toc. After the oral administration of single dose of the placebo or $\gamma$ Toc, the rat urine was collected for $24 \mathrm{~h}$ (divided into $6 \mathrm{~h}$ periods) and the sodium content was measured. The values are the mean \pm SEM of $4-6$ rats, $* p<0.05$, ${ }^{* *} p<0.01$ vs placebo at each time period.

group given a placebo at each time period (Fig. 5). The peak level in the $\mathrm{NaCl}$ group given $20 \mathrm{mg} \gamma$-Toc between $12-18 \mathrm{~h}$ was the same as the result in our previous report [12]. A positive correlation was seen between sodium excretion and 
$\gamma$-CEHC excretion in rat urine of the $\mathrm{NaCl}$ group $\left(r^{2}=\right.$ $0.1061, p<0.05)$. On the other hand, no substantial changes were observed them in rat urine of the control group $\left(r^{2}=0.0536\right)$ (Fig. 3B). Furthermore, $\gamma$-Toc administration has a positive relationship with sodium excretion in a dosedependent manner in rats fed a control diet $\left(r^{2}=0.2115\right.$, $p<0.05)$ and $5 \% \mathrm{NaCl} \operatorname{diet}\left(r^{2}=0.4528, p<0.001\right)$ (Fig. 3C). In contrast, no substantial changes were observed in the potassium excretion rates in the rat urine in all experimental groups (Fig. 6).

According to these findings, $\gamma$-Toc accelerates sodium excretion in a dose-dependent manner in rats with a high sodium intake, however, $\gamma$-Toc has no effect on potassium excretion.

\section{Discussion}

$\gamma$-CEHC, a $\gamma$-Toc metabolite, has exhibited important pharmacological activities as a natriuretic factor in recent studies [7-9]. We previously showed that $\gamma$-Toc had a natriuretic potency after the oral administration of $20 \mathrm{mg}$ $\gamma$-Toc in rats fed a $5 \% \mathrm{NaCl}$ diet [12]. In this study, we investigated whether $\gamma$-Toc accelerated sodium excretion in a dose-dependent manner ( $\gamma$-Toc $10 \mathrm{mg}, 20 \mathrm{mg}$ and $40 \mathrm{mg}$ ) in rats fed a $5 \% \mathrm{NaCl}$ diet.

The 24-h urine sodium contents in the groups given $20 \mathrm{mg}$ and $40 \mathrm{mg} \gamma$-Toc were significantly higher than those in the group given a placebo (Fig. 5). The urine sodium content increased in a dose-dependent manner in groups given $20 \mathrm{mg}$ and $40 \mathrm{mg} \gamma$-Toc. The 24 -h urine $\gamma$-CEHC contents in the groups given $10 \mathrm{mg}, 20 \mathrm{mg}$, and $40 \mathrm{mg} \gamma$-Toc were also significantly higher than those in the control group (Fig. 2). Furthermore, $\gamma$-Toc administration has a positive relationship with $\gamma$-CEHC and the sodium excretion in a dose-dependent manner in all groups (Fig. 3A, 3C). On the other hand, there was a positive relationship between sodium excretion and $\gamma$-CEHC excretion only in the $\mathrm{NaCl}$ group (Fig. 3B).These results indicate that the rate of sodium excretion will increase as the dose of $\gamma$-CEHC increases only with a high sodium intake.

The levels of sodium excretion and $\gamma$-CEHC in the $\mathrm{NaCl}$ group given $40 \mathrm{mg} \gamma$-Toc were significantly higher than the $\mathrm{NaCl}$ group given a placebo during the 0 to 6 hour period (Figs. 2, 5). In the $\mathrm{NaCl}$ group given $40 \mathrm{mg} \gamma$-Toc, the peak levels of urine sodium and $\gamma$-CEHC excretion appeared at 12 hours, which was faster rate than that in the group given $20 \mathrm{mg} \gamma$-Toc (Figs. 2, 5). The time lag in peak levels was investigated in our previous studies comparing $\gamma$-Toc and $\gamma$-tocotrienol $[12,16]$. We compared the rate of sodium and $\gamma$-CEHC excretion between $\mathrm{NaCl}$ groups given $\gamma$-Toc and $\gamma$-tocotrienol. The peak sodium content level of the groups given $\gamma$-tocotrienol $(0-12 \mathrm{~h})$ appeared 6 hours before the peak sodium content level in the group given $\gamma$-Toc $(6-12 \mathrm{~h})$.
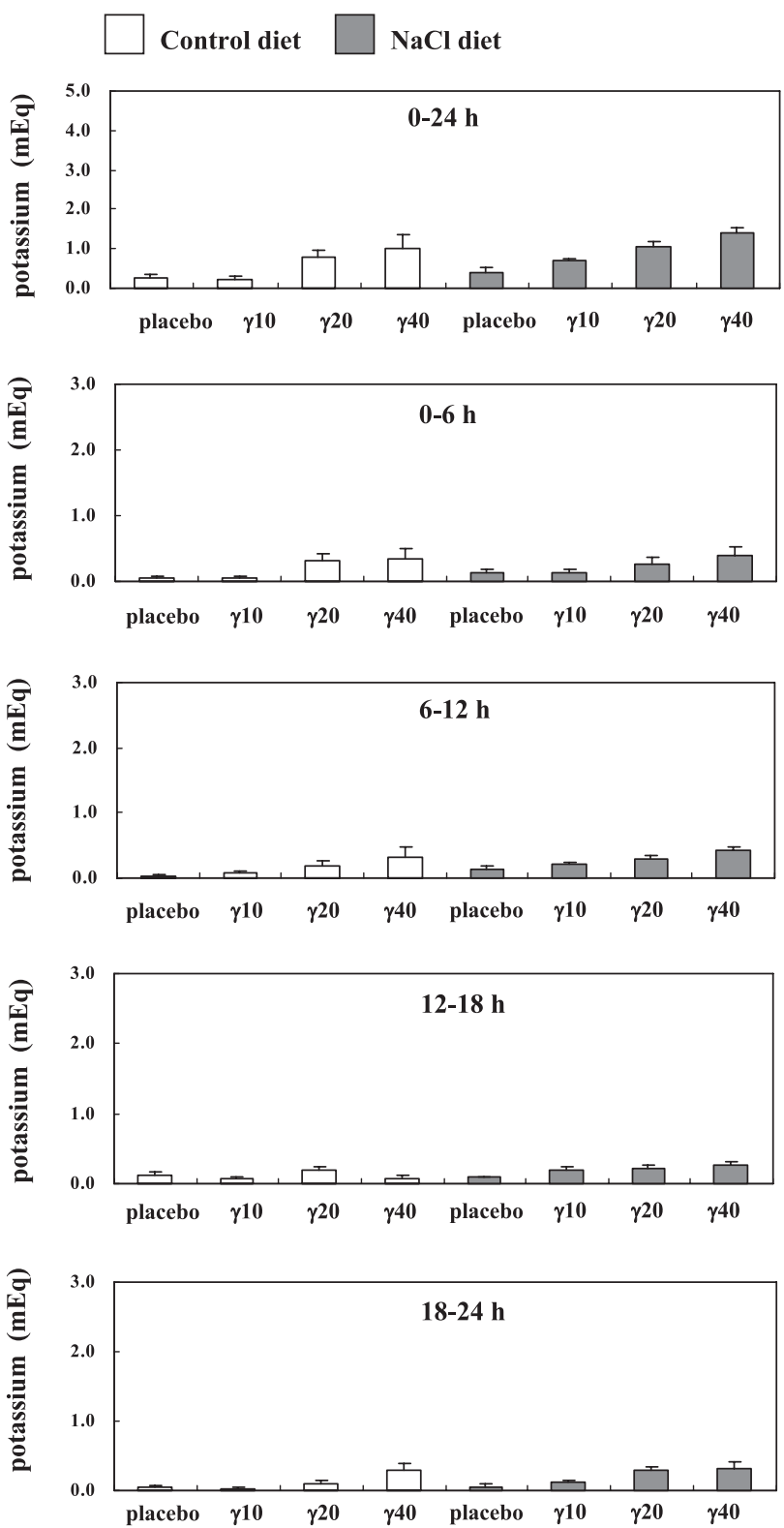

Fig. 6. Changes in the urine potassium content after the oral administration of placebo or $\gamma$-tocopherol $(\gamma$-Toc). The rats were fed a vitamin E-deficient diet (control) or a $\mathrm{NaCl}$ diet for 4 weeks. In each group, one subgroup was administered a placebo, while the others were given $10 \mathrm{mg}(\gamma 10), 20 \mathrm{mg}(\gamma 20), 40 \mathrm{mg}(\gamma 40)$ of $\gamma$-Toc. After the oral administration of single dose of the placebo or $\gamma$ Toc, the rat urine was collected for $24 \mathrm{~h}$ (divided into $6 \mathrm{~h}$ periods) and the potassium content was measured. The values are the mean \pm SEM of 4-6 rats.

Regarding these time lags, we presumed that a higher dose of $\gamma$-Toc enhanced its metabolism as well as the rate of sodium excretion in rats with a high sodium intake. We presumed that the metabolism of $\gamma$-Toc accelerates with a high sodium intake. 
We therefore conclude that $\gamma$-Toc stimulates the urinary output only in the presence of a high sodium intake. It is assumed that there may be a relationship between sodium excretion and the production of $\gamma$-CEHC.

The urine volume in the $\mathrm{NaCl}$ group given $40 \mathrm{mg} \gamma$-Toc was similar to urine volume in the $\mathrm{NaCl}$ group given placebo (Fig. 4). The reason for this similarity was not clear because we did not measure the quantity of water consumed by the rats, but we presumed that rats in the $\mathrm{NaCl}$ group given $\gamma$-Toc $40 \mathrm{mg}$ drank a small quantity of water. There was no significant differences in the urine potassium content in any of the experimental groups (Fig. 6). This result was consistent with our previous reports $[12,10]$. The similar levels of potassium excretion are due to the fact that $\gamma$ CEHC inhibits the 70pS ATP-sensitive $\mathrm{K}^{+}\left(\mathrm{K}_{\text {ATP }}\right)$ channel in the thick ascending limb of the loop of Henle [7-9].

Antihypertensive drugs usually excrete potassium along with sodium, which results in hypokalemia $[17,18]$. However, $\gamma$-Toc might effectively increase the rate of sodium excretion while maintaining the serum potassium level. In conclusion, a high dose of $\gamma$-Toc accelerated the rate of sodium excretion and its metabolism; however, such a dose of $\gamma$-Toc might not increase the urine volume in rats fed a $\mathrm{NaCl}$ diet.

\section{Acknowledgments}

This work was supported by Eisai Co. (Tokyo, Japan). We also thank Dr. H. Kurata, Jikei University School of Medicine, Tokyo, Japan, for helpful discussions.

\section{Abbreviations}

$\gamma$-Toc, $\gamma$-tocopherol; $\quad \gamma$-CEHC, 2,7,8-trimethyl-2-(2'carboxyethyl)-6-hydroxychroman.

\section{References}

[1] Cailar, D.U., Ribstein, J., and Mimran, A.: Dietary sodium and target organ damage in essential hypertension. Am. J. Hyperten., 15, 222-229, 2002.

[2] Antonios, T.F. and Macgregor, G.A.: Salt intake: potential deleterious effects excluding blood pressure, J. Hum. Hypertens., 9, 511-515, 1995.

[3] Yamori, Y., Liu, L., Mu, L., Zhao, H., Pen, Y., Hu, Z., Kuga, S., Negishi, H., and Ikeda, K.: Japan-China cooperative study group. chongqing project. Diet-related factors, educational levels and blood pressure in a Chinese population sample: findings from the Japan-China Cooperative Research Project, Hypertens. Res., 25, 559-564, 2002.

[4] Ministry of Health, Labor and Welfare, Japan: The National Nutrition Survey in Japan 2002. Dai-ichi Shuppan Press, Tokyo, pp.182, 2004.

[5] Kingman, M.S., Thompson, B.S., Newkirk, T., and Torres,
F.: Nesiritide for pulmonary arterial hypertension with decompensated cor pulmonale, Prog. Cardiovasc. Nurs., 20, 168-172, 2005.

[6] Yap, L.B., Mukerjee, D., Timms, P.M., Ashrafian, H., and Coghlan, J.G: Natriuretic peptides, respiratory disease, and the right heart, Chest, 126, 1330-1336, 2004.

[7] Wechter, W.J., Kantoci, D., Murray, E.D. Jr., D'amico, D.C., Jung, M.E., and Wang, W.H.: A new endogenous natriuretic factor: LLU- $\alpha$, Proc. Nat. Acad. Sci. U.S.A., 93, 6002-6007, 1996.

[8] Kantoci, D., Wechter, W.J., Murray, E.D. Jr., Dewind, S.A., Borchardt, D., and Kban, S.I.: Endogenous natriuretic factors 6: the stereochemistry of a natriuretic gamma-tocopherol metabolite LLU-alpha, J. Pharmacol. Exp. Ther, 282, 648656, 1997.

[9] Murray, E.D. Jr., Wechter, W.J., Kantoci, D., Wang, W.H., Pham, T., Quiggle, D.D., Gibson, K.M., Leipold, D., and Anner, B.M.: Endogenous natriuretic factors 7: Biospecificity of a natriuretic $\gamma$-Toc metabolite LLU- $\alpha$, J. Pharmacol. Exp. Ther., 282, 657-662, 1997.

[10] Hosomi, A., Arita, M., Sato, Y., Kiyose, C., Ueda, T., Igarashi, O., Arai, H., and Inoue, K.: Affinity for $\alpha$-Tocopherol transfer protein as a determinant of the biological activities of vitamin E analogs, FEBS Lett., 409, 105-108, 1997.

[11] Schultz, M., Leist, M., Petrzika, M., Gassmann, B., and Brigelius-Flohe, R.: Novel urinary metabolite of alpha-tocopherol, 2,5,7,8-tetramethyl-2(2'-carboxy ethy-6-hydroxychroman, as an indicator of an adequate vitamin E supply?, Am. J. Clin. Nut., 62, 1527S-1534S, 1995.

[12] Uto, H., Kiyose, C., Saito, H., Ueda, T., Nakamura, T., Igarashi, O., and Kondo, K.: Gamma-tocopherol enhances sodium excretion as a natriuretic hormone precursor, J. Nutr. Sci. Vitaminol., 50, 277-282, 2004.

[13] Hervey, G.R.: Determination of creatinine by the Jaffe reaction, Nature, 171, 1125, 1953.

[14] Kayser, F. and Molitor, A.: Critical study of the application of the Jaffe reaction to the determination of creatinine in blood and urine, Ann. Pharm. Fr., 14, 197-208, 1956.

[15] Jacobson, H.: Analysis with ion-specific electrodes, Ann. N. Y. Acad. Sci., 153, 486-492, 1968.

[16] Pelleg, A. and Levy, G.B.: Determination of $\mathrm{Na}^{+}$and $\mathrm{K}^{+}$in urine with ion-selective electrodes in an automated analyzer, Clin. Chem., 21, 1572-1574, 1975.

[17] Kiyose, C., Saito, H., Kaneko, K., Hamamura, K., Tomioka, M., Ueda, T., and Igarashi, O.: $\alpha$-Tocopherol affects the urinary and biliary excretion of 2,7,8-trimethyl-2-(2'-carboxyethyD6-hydroxychroman, $\gamma$-tocopherol metabolite, in rats, Lipids, 36, 467-472, 2001.

[18] Saito, H., Kiyose, C., Yoshimura, H., Ueda, T., Kondo, K., and Igarashi, O.: Gamma-tocotrienol, a vitamin E homolog, is a natriuretic hormone precursor, J. Lipid. Res., 44, 15301535, 2003.

[19] Kokko, J.P.: Site and mechanism of action of diuretics, Am. J. Med., 77, 11-17, 1984.

[20] Reyesa, J.: Diuretics in the therapy of hypertension, J. Hum. Hypertens., 16, S78-S83, 2002. 